OPEN ACCESS

Edited by:

Philippe Saas,

U1098 Interactions Hôte-Greffon-

Tumeur \& Ingénierie Cellulaire

et Génique (INSERM), France

Reviewed by:

Elisa Corsiero,

Queen Mary University of London,

United Kingdom

Gunnar Houen,

Statens Serum Institut

(SSI), Denmark

*Correspondence:

Su-Jin Moon

prajna79@catholic.ac.kr

Ji Hyeon Ju

juj@catholic.ac.kr

Specialty section:

This article was submitted to

Autoimmune and

Autoinflammatory Disorders,

a section of the journal

Frontiers in Immunology

Received: 07 April 2021

Accepted: 02 June 2021

Published: 30 June 2021

Citation:

Won $P$, Kim $Y$, Jung $H$,

Rim YA, Sohn DH, Robinson WH,

Moon S-J and Ju JH (2021)

Pathogenic Role of Circulating

Citrullinated Antigens and Anti-Cyclic

Monoclonal Citrullinated Peptide Antibodies in Rheumatoid Arthritis.

Front. Immunol. 12:692242.

doi: 10.3389/fimmu.2021.692242

\section{Pathogenic Role of Circulating Citrullinated Antigens and Anti-Cyclic Monoclonal Citrullinated Peptide Antibodies in Rheumatoid Arthritis}

\author{
Pureun Won ${ }^{1,2}$, Youngkyun Kim ${ }^{1,2,3}$, Hyerin Jung ${ }^{1,2}$, Yeri Alice Rim ${ }^{1,2}$, \\ Dong Hyun Sohn ${ }^{4,5,6}$, William H. Robinson ${ }^{4,5}$, Su-Jin Moon ${ }^{7 *}$ and Ji Hyeon Ju ${ }^{1,2,8 *}$ \\ ${ }^{1}$ Clinical Immunology and Stem Cell Laboratory (CISTEM) Laboratory, Catholic Induced Pluripotent Stem Cell (iPSC) \\ Research Center, College of Medicine, The Catholic University of Korea, Seoul, South Korea, ${ }^{2}$ Department of Biomedicine \& \\ Health Science, Seoul St. Mary's Hospital, College of Medicine, The Catholic University of Korea, Seoul, South Korea, \\ ${ }^{3}$ Oncology and Immunology Research Center, Lucky-Goldstar (LG) Chem., LG Science Park, Seoul, South Korea, \\ ${ }^{4}$ Department of Veterans Affairs (VA) Palo Alto Healthcare System, Palo Alto, CA, United States, ${ }^{5}$ Division of Immunology \\ and Rheumatology, Stanford University School of Medicine, Stanford, CA, United States, ${ }^{6}$ Department of Microbiology and \\ Immunology, Pusan National University School of Medicine, Yangsan, South Korea, ${ }^{7}$ Division of Rheumatology, Department \\ of Internal Medicine, Uijeongbu St. Mary's Hospital, College of Medicine, The Catholic University of Korea, Seoul, South \\ Korea, ${ }^{8}$ Division of Rheumatology, Department of Internal Medicine, Seoul St. Mary's Hospital, College of Medicine, The \\ Catholic University of Korea, Seoul, South Korea
}

We examined whether it is possible to directly detect citrullinated antigens in the serum of rheumatoid arthritis $(R A)$ patients using a monoclonal antibody (mAb) designed to be specific for citrullinated peptides. In order to confirm the potential of the mAb as a direct arthritis-inducing substance through experimental model of RA, a monoclonal antibody (mAb) 12G1 was generated using by immunization of mice with a challenging cyclic citrullinated peptide. Immunohistochemical analysis of RA-affected synovial tissue showed that our mAb 12G1 could indeed detect citrullinated proteins in target tissues. Subsequently, serum levels of citrullinated type II collagen and filaggrin were measured in healthy volunteers, patients with RA, ankylosing spondylitis (AS), and systemic lupus erythematosus (SLE) using a 12G1-based sandwich ELISA. This showed that citrullinated filaggrin showed $78.9 \%$ sensitivity and $85.9 \%$ specificity for RA diagnosis with a cutoff optical density (OD) value of 1.013, comparable with the results from a second-generation anti-citrullinated protein antibody (ACPA) test. Circulating citrullinated collagen and filaggrin were detected even in sera of RA patients who were negative for both rheumatoid factor (RF) and ACPA. ELISA results also showed that RF and ACPA titers showed significantly positive correlation with both citrullinated collagen and filaggrin OD values in sera of RA patients. 12G1 challenging aggravated the severity of murine arthritis. In summary, mAb 12G1 can directly detect citrullinated proteins in RA target tissue and in sera of RA patients and 12G1 showed direct arthritogenic potential in vivo. This, 12G1 might be useful for diagnosis of RA including seronegative RA and may help to elucidate the pathophysiological role of citrullination in RA.

Keywords: rheumatoid arthritis, citrullination, cyclic citrullinated peptide, monoclonal antibody, diagnosis 


\section{INTRODUCTION}

Rheumatoid arthritis (RA) is a chronic, systemic inflammatory disease characterized by inflammation of the synovial membrane lining the joints and progressive joint damage. Although the pathogenesis of RA remains uncertain, it is increasingly clear that altered cellular immune responses play a role (1). The presence of autoreactive $\mathrm{T}$ cells and autoantibodies are the main characteristics of RA, and both are detectable in the earliest stages of the disease. Autoantibodies, including rheumatoid factor (RF), can be detected in serum and synovial fluid (SF) samples from RA patients.

Citrullination is a post-translational modification performed by the enzyme peptidyl-arginine deiminase (PAD), which converts the amino acid arginine into the noncoded amino acid citrulline. This modification can be detected in the inflamed joints of mice and in RA-affected synovial tissue in humans (2-6). Proteins harboring citrullinated epitopes are the dominant antigens recognized by autoantibodies in serum from RA patients $(7,8)$. For example, filaggrin contains many arginine residues, and citrullinated anti-filaggrin antibodies purified from RA sera can recognize (pro)filaggrins only when the filaggrins are citrullinated.

The presence of anti-citrullinated protein antibodies (ACPAs) is a hallmark of RA (9). After the presence in the blood of RA patients and its clinical significance of ACPA was revealed, the pathophysiological significance of ACPA or citrullination has been shown through numerous studies (10, 11). As the generation of citrullinated antigens and resulting ACPA is directly involved in RA pathogenesis regarding the development or progression of the disease, studies have been conducted on the expression of ACPA-producing B cells and its immunological characters $(12,13)$. Recent studies showed a mechanism of epitope spreading of ACPA response against citrullinated antigens through ACPA plasmablast repertoires $(14,15)$. Indeed, ACPA derived from RA patients can specifically recognize citrulline residue largely independent of the peptide epitope sequence (16). One recent paper by Tilvawala et al. showed that RA-associated citrullinated proteins in sera, synovial fluids, and synovial tissues samples by proteomic analysis (17). They identified more than 150 novel citrullinated proteins and validated the role of citrullination on target proteins identified in their study (17).

Based on the previous reports that citrullinated antigens are present in joints, synovial fluid and synovial tissues of RA patients, it is possible that soluble citrullinated autoantigens can be detected in the serum or SF of RA patients using a sandwich enzyme-linked immunosorbent assay (ELISA). Some previous studies have verified a method for detecting citrullination. Senshu et al. developed a method for detecting citrullinated proteins using polyvinylidene difluoride membranes (18). A decade after that report, an $\operatorname{IgM}$ monoclonal antibody $(\mathrm{mAb})$, designated F95, was developed using hybridoma technology (19). F95 staining revealed the increased presence of intracellular citrullinated proteins in RAaffected synovial tissue (53\%) compared with control tissue (5\%), but the extracellular staining pattern from F95 was not RA- specific. F95 was generated against a deca-citrullinated peptide comprising 10 citrulline residues and a carrier protein, and it was inconclusive whether F95 could distinguish citrulline residues from arginine residues in the target proteins. No study has reported the detection of intact citrullinated peptides with an artificially designed antibody specific for circular citrullinated peptides (CCPs).

The goal of the present study was to generate a mAb that recognizes diverse citrullinated proteins and to confirm its ability to detect citrullinated autoantigens directly in RA samples. We generated $\mathrm{mAb}$, named $12 \mathrm{G} 1$, to detect citrullinated proteins directly in RA-affected synovial tissue. A sandwich ELISA was developed based on 12G1-detected citrullinated autoantigens in sera from RA patients. The levels of citrullinated collagen, and filaggrin were significantly higher in RA sera than in sera of healthy control, ankylosing spondylitis (AS), or systemic lupus erythematosus (SLE) patients. Interestingly, higher citrullinated filaggrin levels were detected in RA patients who had neither RF nor ACPA (seronegative) compared with controls. The optical density (OD) values of citrullinated collagens and filaggrin in RA patients correlated positively with both the rheumatoid factor (RF) and ACPA titers. 12G1 showed arthritogenic potential in a murine model of inflammatory arthritis in our present study.

\section{MATERIALS AND METHODS}

\section{Mice}

Female BALB/c mice (6 weeks of age) and female DBA1/J mice (5 weeks of age) were purchased from OrientBio (Seongnam, Korea) and housed in specific pathogen-free conditions. All procedures involving animals were in accordance with the Laboratory Animals Welfare Act, the Guide for the Care and Use of Laboratory Animals, and the Guidelines and Policies for Rodent Experimentation provided by the Institutional Animal Care and Use Committee of the School of Medicine at the Catholic University of Korea. This study protocol was approved by the Institutional Review Board of the Catholic University of Korea (CUMC-2011-0062-03 and CUMC-20180338-01).

\section{Immunization of Mice and Preparation of the mAb}

A CCP (HQCHQESTXGRSRGRCGRSGS; $\mathrm{X}=$ citrulline) and a noncitrullinated peptide (NCP: HQCHQESTRGRSRGRCGRSGS) were synthesized. The synthetic CCP was mixed with complete Freund's adjuvant and used to immunize four 6-week-old female BALB/c mice via injection into the abdominal cavity. For boosting, the mice were injected with CCPs diluted in phosphate-buffered saline (PBS) 4 and 8 weeks after the first immunization. Three days later, B cells were isolated from the mouse with the highest binding reactivity against the CCPs in serum, as measured by ELISA (details are provided in the method described below) and fused with myeloma cells (Sp2/0-Ag14) using polyethylene glycol (Roche, Basel, Switzerland).

The fused cells were then cultured in hypoxanthineaminopterin-thymidine culture medium (Sigma, St. Louis, 
MO, USA). Cells showing a positive signal in the ELISA were transferred to a 24-well plate. After individual cells were placed into separate wells in 96-well plates, the cells were cultured for 710 days in hypoxanthine and thymidine culture medium (Gibco/ Thermo Fisher Scientific, Waltham, MA, USA) in a 5\% CO2 incubator at $37^{\circ} \mathrm{C}$. Hybridoma cells were screened by ELISA, and the cloning process was repeated until the final antibodysecreting clone was selected.

\section{ELISA for Antibody Screening}

CCPs and NCPs (negative control) were diluted to $5 \mu \mathrm{g} / \mathrm{ml}$ in coating buffer, and $50 \mu \mathrm{l}$ were coated in separate wells of an ELISA plate either overnight at $4^{\circ} \mathrm{C}$ or for 2 hours at $37^{\circ} \mathrm{C}$. The plates were blocked with $2 \%$ skimmed milk in Tris-buffered saline with Tween 20 at $37^{\circ} \mathrm{C}$ for 1 hour. Serum from immunized mice or the supernatant from the hybridoma cells was added to the wells, and the plates were incubated for 2 hours at RT. The plates were washed, and $50 \mu \mathrm{l}$ of horseradish peroxidase (HRP)conjugated goat anti-rabbit IgG was added to each well for 1 hour at RT. Finally, $50 \mu \mathrm{l}$ of chromogenic substrate (SurModics, Eden Prairie, MN, USA) was added to each well, and the plates were incubated for 30 minutes, after which $50 \mu$ l of stop solution (1N H2SO4) was added. The absorbance was read at $450 \mathrm{~nm}$ in a VERSAmax ELISA reader. Serum samples were collected from mice 4 weeks after their primary immunization and tested as just described.

\section{Total RNA Extraction and Synthesize cDNA of Antibody Variable Regions}

The monoclonal antibody-producing hybridoma cells were generated as described above (2.2), and total RNA was extracted using the Easy-Blue total RNA extraction kit (Intron Biotechnology, Sungnam, Korea) according to the manufacturer's instructions. In addition, oligo dT primer with reverse transcriptase (Promega, Madison, WI, USA) was used to reverse transcribe the extracted RNA into cDNA, and heavy and light chain genes of our synthetic monoclonal antibody were amplified from cDNA using Ex-Taq DNA polymerase (Takara Bio, Shiga, Japan) with specific primers described (20) and cloned whole amino acids and nucleotides for the antibody using as described (20).

\section{In Vitro Citrullination}

Human type II collagen (Creative Biomart, Shirley, NY, USA), fibronectin (Sigma-Aldrich/Thermo Fisher Scientific), and filaggrin (Biomatik, Cambridge, Ontario, Canada) were subjected to in vitro citrullination with PAD derived from rabbit skeletal muscle (Sigma-Aldrich) at 5 units/mg of protein for 3 hours at $48^{\circ} \mathrm{C}$ in citrullination buffer containing $100 \mathrm{mM}$ Tris- $\mathrm{HCl}$ (pH 7.4), $10 \mathrm{mM} \mathrm{CaCl}$, and $5 \mathrm{mM}$ dithioerythritol.

\section{Detection of In Vitro Citrullinated Proteins by Artificial Anti-Citrullinated Protein Antibody}

In the ELISA, 96-well plates were coated with $10 \mu \mathrm{g} / \mathrm{ml}$ of in vitro citrullinated and non-citrullinated proteins overnight at $4^{\circ} \mathrm{C}$.
Plates were washed and blocked with $1 \%$ BSA for 1 hour at $\mathrm{RT}$, washed again, and incubated with $20 \mu \mathrm{g} / \mathrm{ml}$ of the $\mathrm{mAb}$ 12G1 for 2 hours at RT followed by incubation with HRPconjugated anti-mouse IgG for 1 hour at RT. The OD at $450 \mathrm{~nm}$ was measured after treatment with 3,3',5,5'-Tetramethylbenzidine (TMB substrates; ebioscience/Thermo Fisher Scientific) and stop solution $\left(1 \mathrm{~N} \mathrm{H}_{2} \mathrm{SO}_{4}\right)$.

\section{Western Blotting and Isotyping}

The synthetic peptides, CCPs and NCPs, are too small to be detected by Western blotting, so we conjugated them to BSA. Citrullinated and non-citrullinated proteins were loaded onto SDS-PAGE gels. After electrophoresis, the proteins were transferred to nitrocellulose membranes, which were then incubated with the antibody of interest in blocking buffer (5\% skimmed milk in PBS containing 0.05\% Tween 20 (PBS-T)) for 1 hour at RT or $12-14$ hours at $4^{\circ} \mathrm{C}$. After washing with blocking buffer, the bound antibodies were detected by incubation with HRP-conjugated secondary antibodies and visualized by chemiluminescence. The subtype of mAb 12G1 was analyzed using the mouse monoclonal antibody isotyping kit (Invitrogen/ Thermo Fisher Scientific, Waltham, MA, USA) following the manufacturer's instruction.

\section{Immunohistochemistry}

Synovial tissues from RA patients, OA patients, and healthy donors were embedded in paraffin, sectioned, mounted on slides, and baked at $60^{\circ} \mathrm{C}$ for 60 minutes. The sections were then deparaffinized and rehydrated through a series of graded alcohols, ending with a rinse in tap water. The slides were incubated with $3 \%$ hydrogen peroxide for 15 minutes to block endogenous peroxidase. Next, the slides were washed with tap water and blocked with $10 \%$ normal horse serum plus $1 \%$ BSA in PBS. After washing with PBS-T, the slides were incubated with the mAb $12 \mathrm{G} 1$ (1:50) overnight at $4^{\circ} \mathrm{C}$. A biotinylated horse antimouse IgG secondary antibody (1:200) was applied for 40 minutes at RT, followed by the R.T.U. VECTASTAIN ${ }^{\circledR}$ Elite $\mathrm{ABC}$ reagent for 10 minutes. Tissue staining was visualized after incubation with the DAB substrate chromogen solution (Vector Laboratories, Burlingame, CA, USA) for 1 minute 30 seconds. Slides were counterstained with hematoxylin for 1 minute, dehydrated, and mounted.

For mouse tissue, joints were embedded in paraffin, sectioned, deparaffinized in xylene, and hydrated using serially diluted ethanol ending with a rinse in tap water. To block endogenous peroxidase, the sections were incubated in $3 \% \mathrm{H}_{2} \mathrm{O}_{2}$ diluted in PBS for $15 \mathrm{~min}$ and washed with tap water. The slides were incubated with Mouse on Mouse (M.O.M.) IgG blocking agent from a M.O.M. Basic Kit for $30 \mathrm{~min}$ to block nonspecific antibody binding. The 12G1 mAb (1:100) was diluted in M.O.M. diluent buffer and incubated overnight at $4^{\circ} \mathrm{C}$. A biotinylated anti-mouse Ig reagent was applied for $10 \mathrm{mins}$ at RT followed by R.T.U. VECTASTAIN ${ }^{\circledR}$ Elite ABC reagent for 10 mins. The sections were then incubated with DAB solution for $1 \mathrm{~min}$. Slides were counterstained with hematoxylin for 30 secs, dehydrated, and mounted. 
For all cases, the isotype (negative) control was a mouse IgG2 mAb (Cell Signaling Technology, Danvers, MA, USA) and the slides were visualized using Leica DM500B imaging system (Leica Microsystems Ltd., Wetzlar, German).

\section{Sandwich ELISA for the Detection of Citrullinated Proteins in Human Serum}

Briefly, 96-well microtiter plates were coated with polyclonal anticollagen (Abcam, Cambridge, UK), anti-filaggrin (Santa Cruz Biotechnology, Dallas, Texas, USA), or anti-fibronectin (Abcam) antibodies (1:100 dilution) in 100 $\mu$ l of coating buffer (eBioscience) and incubated overnight at $4^{\circ} \mathrm{C}$. The plates were washed seven times with PBS-T and incubated with assay buffer (eBioscience) for $1 \mathrm{~h}$ at room temperature (RT). The plates were again washed seven times with PBS-T. Serum samples (1:10 diluted in PBS) were added to each well in triplicate, and the plates were incubated for $2 \mathrm{~h}$ at RT. The plates were washed seven times with PBS-T, and then the $12 \mathrm{G} 1$ $\mathrm{mAb}$ (1:100 diluted in assay buffer) was added, and the plates were incubated for $2 \mathrm{~h}$ at RT. After incubation, the plates were washed seven times in PBS-T, 50 $\mu$ l of HRP-conjugated anti-mouse IgG antibody (1:3000, Amersham Pharmacia Biotech, Amersham, Buckinghamshire, UK) was added, and the plates were incubated for a further 1 hour at $37^{\circ} \mathrm{C}$. Finally, the plates were washed nine times, and the bound antibodies were visualized by adding substrate solution (eBioscience). Reactions were stopped after 15 mins by adding $50 \mu \mathrm{l}$ of stop solution (eBioscience). The colorimetric reaction was measured at $450 \mathrm{~nm}$ on a VersaMax ELISA reader.

\section{Human Subjects}

Synovial tissue samples were obtained from RA patients and OA patients at the time of total knee replacement surgery. Serum samples were obtained from 148 RA patients (106 women and 42 men), 57 AS patients (18 women, and 39 men), and 60 SLE patients (1 man, and 59 women) who visited the Outpatient Department of the Division of Rheumatology at Seoul St. Mary's Hospital at the Catholic University of Korea between May 2015 and August 2018. All RA patients who met both the American College of Rheumatology (ACR) criteria for RA (21) and the 2010 ACR/European League Against Rheumatism criteria (22) were included in the study. AS and SLE patients who met ASAS classification criteria (23) and 2012 SLICC SLE criteria (24), respectively. Seventy-one healthy volunteers (62 women and 9 men) were included as controls. Elderly onset RA (EORA) was defined as RA onset age at $\geq 60$ years, and young onset RA (YORA) was defined as RA symptoms developing between the ages of 18 and 59 years. Early RA (ERA) was defined as a disease duration of $<6$ months.

Serum samples were stored at $-80^{\circ} \mathrm{C}$ until analysis. This study was approved by the Institutional Review Board of Seoul St. Mary's Hospital and was performed in accordance with the Declaration of Helsinki. All patients provided written informed consent.

\section{Clinical Data and Measurement of Inflammatory Markers}

Data about the age, sex, disease duration, Erythrocyte sedimentation rate (ESR), C-reactive protein (CRP) level,
ACPA level, and Rheumatoid factor (RF) titer were obtained for each patient. The RF titer was measured using a particleenhanced immunoturbidimetric assay, and a level $>15 \mathrm{U} / \mathrm{ml}$ was considered positive. The ACPA titer was measured in a chemiluminescent microparticle immunoassay (ARCHITECT anti-cyclic citrullinated peptide assay), which is a secondgeneration test for ACPAs; a level higher than the cutoff value of $5 \mathrm{U} / \mathrm{ml}$ was considered positive (as suggested by the manufacturer). ESR was measured using the Westergren method. CRP was measured using an immunonephelometric method, and values $>5 \mathrm{mg} / \mathrm{l}$ were considered positive.

\section{Induction of Mouse Models}

The mice were organized into 4 groups of 5 mice each: CIA (collagen induced arthritis) as the normal control; vehicle as the negative control; $12 \mathrm{G} 1$; and $12 \mathrm{G} 1$ with lipopolysaccharide (LPS). To induce CIA, $2 \mathrm{mg} / \mathrm{ml}$ of bovine type II collagen (CII; Chondrex, Redmond, WA, USA) emulsified with $2 \mathrm{mg} / \mathrm{ml}$ of complete Freund's adjuvant (Chondrex) was given intradermally to 6-week-old DBA1/J mice. After 21 days, the same concentration of CII emulsified with incomplete Freund's adjuvant (IFA; Chondrex) was injected into the CIA mice. To induce arthritis using the $12 \mathrm{G} 1 \mathrm{mAb}, 12 \mathrm{G} 1 \mathrm{mAb}$ diluted with PBS (1.5mg per mouse) was injected instead of the CII and IFA mixture. After 7 days, either the same concentration of $12 \mathrm{G} 1$ $\mathrm{mAb}$ was injected again or LPS was given at $50 \mu \mathrm{g} / \mu \mathrm{l}$. The same concentration of $12 \mathrm{G} 1 \mathrm{mAb}$ was combined with CCP chelating beads (Santa Cruz Biotechnology) for $4 \mathrm{~h}$ at $4^{\circ} \mathrm{C}$, which was followed by centrifugation $(250 \mathrm{~g}, 30 \mathrm{~s})$; the resulting supernatants were collected and injected into the mice as vehicle.

The development of arthritis was monitored and scored in a blinded manner. Disease severity was scored three times a week. The severity of arthritis in each front and hind paw was scored from 0 to 4 ( 0 , normal; 1 , mild swelling confined to the tarsals; 2 , swelling of two or more toes or joints, or increased swelling; 3 , moderate swelling extending from the ankle to the metatarsal joints; and 4, severe swelling encompassing the ankle, foot, and digits). A representative arthritis score was determined by summing the scores of all four paws (25).

\section{Histological Analysis}

Joint tissues from hind paws were fixed in $4 \%$ paraformaldehyde, decalcified in $10 \%$ EDTA bone decalcifying solution, and embedded in paraffin. Paraffin sections of $4 \mu \mathrm{m}$ thickness were prepared and stained with $\mathrm{H} \& \mathrm{E}$, safranin $\mathrm{O}$, and toluidine blue.

The inflammation and joint destruction scores were measured microscopically using the procedure of Huckel et al. by three individual researchers in a blinded manner (26). The inflammation score was measured using the severity of infiltration and pannus formation. The destruction score was measured based on cartilage and bone destruction $(27,28)$.

\section{Flow Cytometry Analysis}

The spleen samples were dissociated into single-cell suspensions, and $2 \times 10^{6}$ cells were transferred to round-bottom polystyrene tubes (BD Biosciences, CA, USA). After washing with PBS 
supplemented with $2 \%$ FBS, mouse spleen cells were stained with a rat anti-mouse CD4 $(2 \mu \mathrm{g} / \mathrm{mL})$ antibody conjugated with allophycocyanin (APC) (eBioscience, CA, USA). The cells were then permeabilized using Flow Cytometry Fixation and Permeabilization buffer (eBioscience) and stained with an antihuman/mouse ROR $\gamma t(2 \mu \mathrm{g} / \mathrm{mL})$ antibody conjugated with phycoerythrin (eBioscience). The flow cytometry analysis was performed using a BD LSR Fortessa cell analyzer (BD Biosciences). To analyze the data, FlowJo V10 Single Cell Analysis Software was used (TreeStar Inc., OR, USA).

\section{Statistical Analysis}

Data were analyzed using SPSS software version 18.0 (SPSS Inc., Chicago, IL, USA) and are expressed as the mean \pm SEM or number (\%). The mean values were compared between multiple groups using one-way analysis of variance followed by Tukey's test. The Shapiro-Wilk test and the Levene test were used to assess Gaussian distributions and the equality of variance, respectively. Qualitative data were compared using the chisquared test. ROC curves were constructed by calculating the specificity and sensitivity of each OD value at different cutoff points, and the area under the curve was computed. Sensitivity was defined as the percentage of subjects with disease (RA or seronegative RA) who showed a positive result for citrullinated antigens in the ELISA. Specificity was defined as the percentage of subjects without RA who had a negative ELISA result. The PPV was calculated as the number of true positives (positive ELISA result plus confirmed RA) divided by the number of subjects with a positive ELISA result. The NPV was calculated as the number of true negatives (negative ELISA result and no RA) divided by the number of subjects with a negative ELISA result. All $P$ values were two-tailed. $P$ values $<0.05$ were considered significant.

\section{RESULTS}

\section{Generation of a mAb Against CCPs}

To identify the presence of circulating autoantigens that could induce the production of ACPAs, we generated a mAb specific for citrullinated antigens. First, we synthesized a CCP and an NCP control peptide (cyclic arginine peptide) in which citrulline was replaced with arginine (Figure 1A). This synthetic peptide included citrulline in a particular region of the filaggrin subunit that is cyclized via a disulfide bond and forms a structure that favors recognition by RA autoantibodies (29). We then used hybridoma technology to generate high-quality mAbs with reactivity for the CCP but not the NCP (Figure 1B). Four mice were immunized with the CCP, and we examined the reactivity of their serum antibodies to the CCP and NCP (Figure 1C). We selected mouse number 2 because its serum samples showed strong binding reactivity to the CCP and weak binding to the control NCP (Figure 1C). Hybridoma clones were generated by fusing a myeloma cell line with $\mathrm{B}$ cells derived from the selected CCP-immunized mouse. We then performed an ELISA to identify antibody-secreting clones that produced anti-
CCP antibodies (Figure 1D and Supplementary Figure 1). This process was repeated until we isolated a single clone (designated $12 \mathrm{G} 1$ ) that secreted a mAb with high reactivity to the CCP but not to the control peptide (asterisk in Figure 1D, final selection). The binding affinity of 12G1 was confirmed (Supplementary Figure 2A). The isotype of the artificial anti-citrullinated protein antibody (12G1) was IgG1, and the V regions of the light and heavy chains of 12G1 were sequenced (Supplementary Figure 2B).

\section{G1 mAb Is Specific for Citrulline}

To confirm that the selected hybridoma cell line could secrete intact $12 \mathrm{G} 1$, we purified the antibody from the culture supernatant using antibody-binding beads (Figure 1E). Subsequent electrophoresis in SDS-PAGE gels confirmed that the purified $12 \mathrm{G} 1$ had a normal antibody structure; i.e., a heavy chain and a light chain (Figure 1E, lanes 4, 5). In addition, to ensure that the $12 \mathrm{G} 1$ recognized citrulline, we performed an immunoblot assay using the CCP and NCP as target antigens (Figure 1F). Because the CCP and NCP were too small to detect using SDS-PAGE gels, we conjugated them to bovine serum albumin (BSA). The $12 \mathrm{G} 1 \mathrm{mAb}$ detected the CCP specifically and in a dose-dependent manner (Figure 1F, lanes 1-4). As expected, the 12G1 mAb did not react with the NCP (Figure 1F, lanes 5-8). These data clearly demonstrate that the $12 \mathrm{G} 1 \mathrm{mAb}$ was specific for the citrullinated peptide. Immunoglobulin isotyping assay showed that the heavy chain and light chain of 12G1 were identified as IgG1 and kappa chain, respectively (Figure 1G). Next, we examined whether the 12G1 mAb could be available in the sandwich ELISA system. If so, we reasoned that our aACPA would have clinical use in the diagnosis of diverse autoimmune and autoinflammatory diseases involving citrullination. In vitro citrullination experiments were performed using PAD. Six naïve target antigens (human type II collagen, filaggrin, enolase, $\mathrm{BiP}$, vimentin, and fibronectin) and their corresponding citrullinated antigens were tested to determine whether the aACPA could detect the citrullinated forms of the target antigens. Among them, citrullinated-collagen, -filaggrin and -fibronectin could be detected by the $12 \mathrm{G} 1$ in the sandwich ELISA system (Figures $\mathbf{1 H}-\mathbf{J}$ ). These results confirm both that our mAb $12 \mathrm{G} 1$ is specific for citrullinated antigens and that it can be used in a sandwich ELISA system.

\section{G1 Detects Citrullinated Autoantigens in Synovial Tissues From RA Patients}

Because citrullinated proteins can be detected in inflamed RA synovial tissue, we next examined whether 12G1 could specifically detect such proteins in synovial tissues isolated from RA patients. Immunohistochemical staining of synovial tissue showed that $12 \mathrm{G} 1$ could detect citrullinated proteins in RA tissues, as we expected (Figure 2A). Control staining of the same tissues with an irrelevant isotype-matched primary antibody gave negative results (Figure 2A, upper panels). 12G1 recognized citrullinated proteins in synovial tissue from three different RA patients. To confirm that 12G1 was specific for citrullination, we also examined synovial tissues isolated from three patients with OA (Figure 2B). No positive staining was 
A
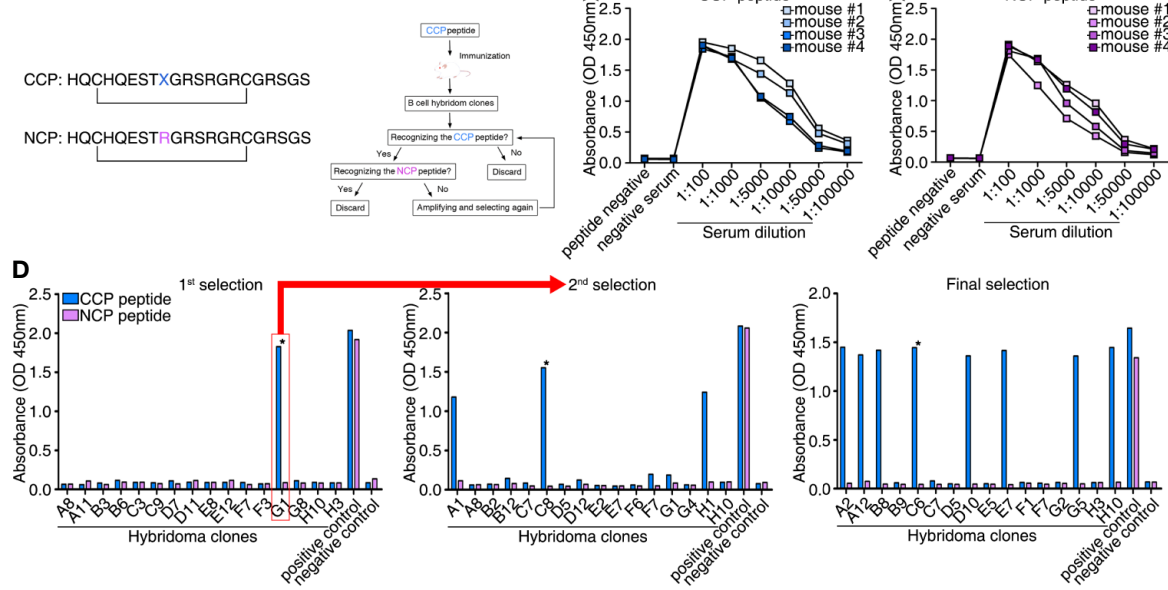

E

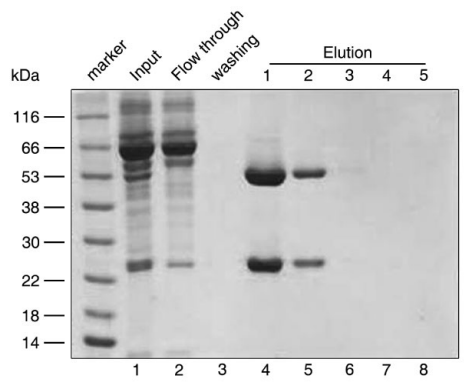

G

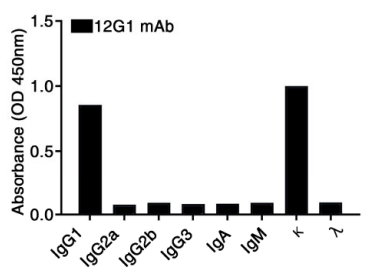

I
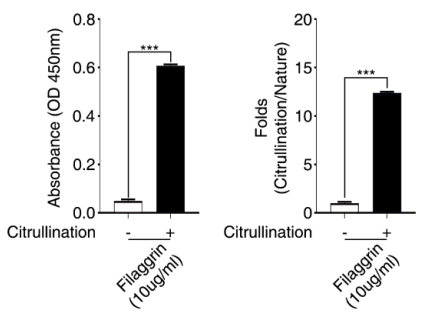

$\mathbf{F}$

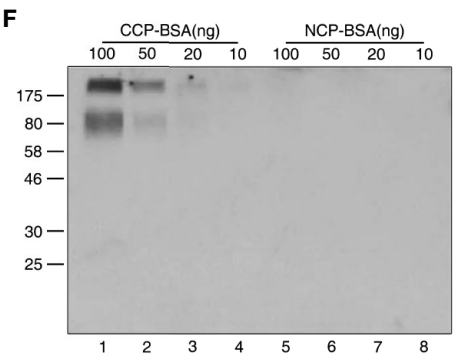

H
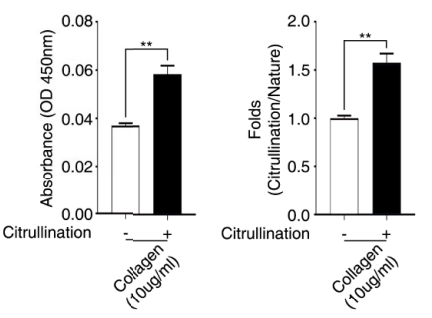

$\mathbf{J}$

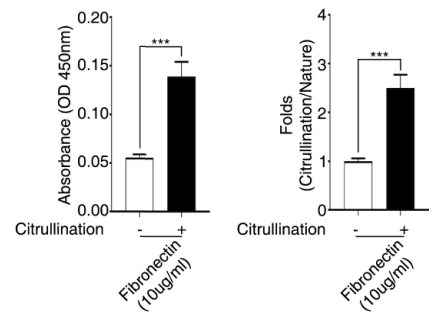

FIGURE 1 | Generation of a cyclic citrullinated peptide (CCP)-specific monoclonal antibody (mAb). (A) Sequences of the two synthetic peptides used as antigens. Both peptides shared the same sequence, except that the CCP was generated by replacing an arginine residue with a citrulline residue $(X=$ citrulline). The bar indicates a disulfide bond between the two cysteines, which generates a circular peptide. (B) Schematic diagram showing the strategy for selecting hybridoma clones. Hybridoma clones that secreted antibodies specific to CCP were obtained by repeated selection. (C) Selection of mice showing seroreactivity against the CCP. After the first injection of the CCP, the binding reactivity to the CCP and the cyclic arginine peptide (NCP) was examined using ELISA (serum samples diluted 1:100 to 1:100000). (D) ELISA of fused hybridoma clones that secreted mAbs to the CCP. After fusion, hybridoma clones secreting anti-CCP antibodies specific for the CCP but not the NCP were selected. Clones reactive to the CCP were isolated and evaluated repeatedly until a single clone secreting high-reactivity anti-CCP antibodies was selected. (E) The 12G1 mAb was purified from the hybridoma culture supernatant using a Protein $\mathrm{G}$ agarose column. After the supernatant (input) was loaded onto the column, bound 12G1 mAb was eluted in the elution buffer (elution). The purified antibody was confirmed by SDS-PAGE and Coomassie brilliant blue staining. (F) The specificity of the 12G1 mAb for the CCP was examined by Western blotting. CCP-BSA and NCP-BSA conjugates were run in an SDS-PAGE gel and then immunoblotted with the 12G1 mAb. (G) mAb 12G1 immunoglobulin isotyping assay (absorbance of positive response $\geq 0.2$ ). (H-J) The 12G1 mAbbased ELISA system effectively detected citrullinated collagen $(\mathbf{H})$, citrullinated filaggrin (I), and citrullinated fibronectin $(\mathbf{J}) .{ }^{\star} P<0.05 ;{ }^{\star \star} P<0.01 ;{ }^{\star \star \star} P<0.001$. 
detected in the $\mathrm{OA}$ tissues. These findings suggest that the citrullinated autoantigens detected by $12 \mathrm{G} 1$ exist in RAaffected synovial tissue but not in OA-affected tissues. Taken together, the data obtained thus far suggest that the 12G1 could detect citrullinated proteins in RA synovial tissue and that it has potential for RA diagnosis. Next, 12G1 was used for tissue staining to determine whether the joints of CIA mice had citrullinated proteins. The results showed that CIA-affected joints contained citrullinated proteins in synovium, but wildtype mice did not (Figure 2C).

\section{Circulating Citrullinated Antigens Are Detected by $12 \mathrm{G} 1$ in Serum From RA Patients}

Citrullination of target epitopes occurs in rheumatoid joints (6). Previous studies have shown that citrullinated proteins such as collagen, filaggrin, and fibronectin are implicated in the pathogenesis of RA $(7,30,31)$. We developed a sandwich ELISA based on $12 \mathrm{G} 1$ to detect only the citrullinated proteins in sera from RA patients (Materials and Methods and Figure 3A). Serum samples were obtained from 148 RA patients and 71 age- and sex-matched healthy controls. To determine whether the presence of circulating citrullinated antigens in blood was RA-specific observation, ELISA was performed simultaneously in the sera of AS and SLE patients (Figure 3B).

The baseline clinical and laboratory characteristics of the patients and controls are presented in Table 1. Most of the RA patients were seropositive for either RF (71\%) or ACPA (79\%). Fifty-two of the RA patients (35.1\%) had ERA (disease duration $<6$ months) and $43(26.1 \%)$ had EORA (age of RA onset $\geq 60$ years). Among RA patients taking medications ( $\mathrm{n}=$ 106), sixty-six (62\%) RA patients had received prednisolone (mean dose $<5 \mathrm{mg} /$ day).

The OD values from the ELISA were analyzed for all the subjects enrolled in our study. The mean OD values for citrullinated collagen, and filaggrin were significantly higher in RA patients than in controls, SLE and AS patients (Figure 3B, upper panel). On the contrary, OD values of fibronectin in sera of RA patients did not increase compared to HC, SLE and AS patients (data not shown). We completed a receiver-operating characteristic (ROC) curve analysis and used the areas under the curve to calculate the diagnostic accuracy of these two target antigens (Figure 3B, lower panel). The mean OD values of citrullinated collagen and filaggrin in healthy controls and RA sera are shown in Supplementary Table 1. ROC curve analysis
A

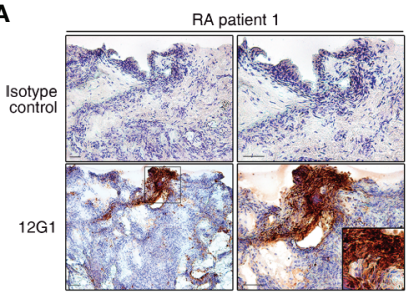

B

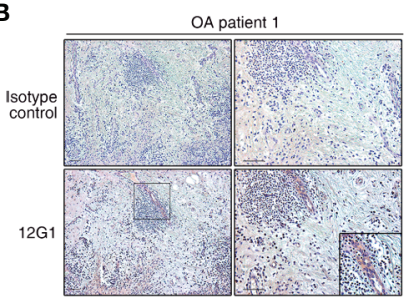

C

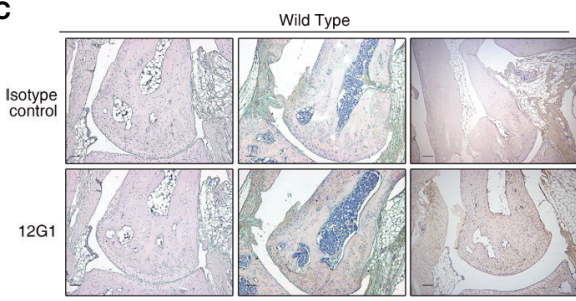

RA patient 2
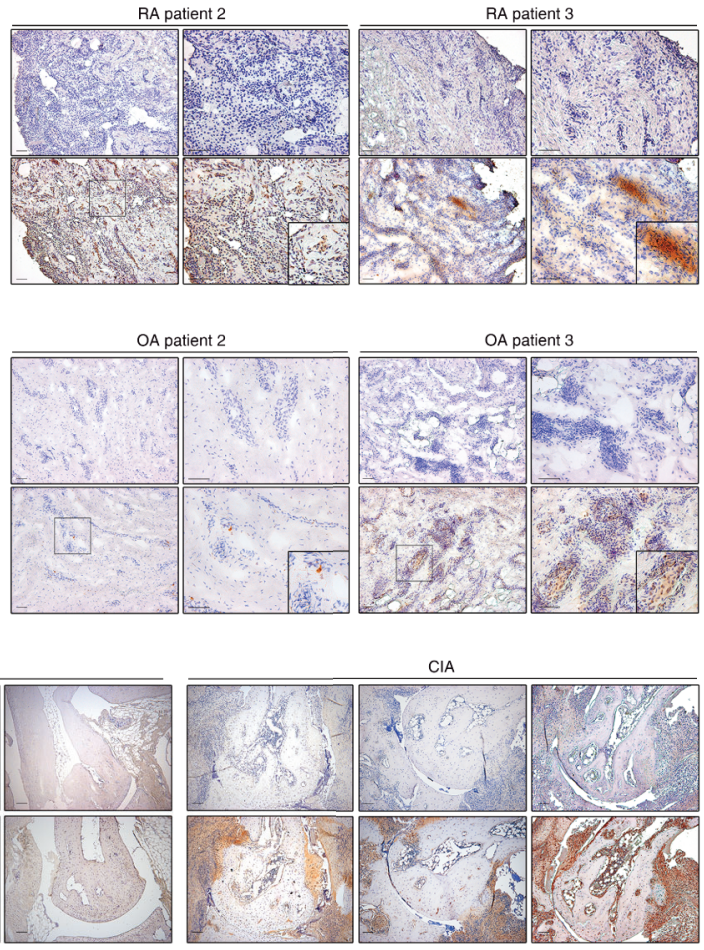

FIGURE 2 | The 12G1 mAb is specific for citrullinated proteins in RA synovial tissue. Representative images showing immunohistochemical (IHC) staining of citrullinated proteins in RA and OA. (A) The IHC analysis was performed using the $12 \mathrm{G} 1 \mathrm{mAb}$ in joint synovium tissue specimens from three RA patients (RA patients 1-3). To ascertain whether any antigens could be detected by the $12 \mathrm{G} 1 \mathrm{mAb}$ in noninflammatory synovial tissues, synovial tissues from three $\mathrm{OA}$ patients (B) were stained with 12G1 mAb at the same time. An isotype control antibody was used as a negative control. (C) A joint with collagen-induced arthritis (CIA) was stained with the $12 \mathrm{G} 1 \mathrm{mAb}$. The black box shows the stained synovial tissue at a higher magnification. The magnification is indicated for each image in this figure. All scale bars represent $100 \mu \mathrm{m}$. 
A

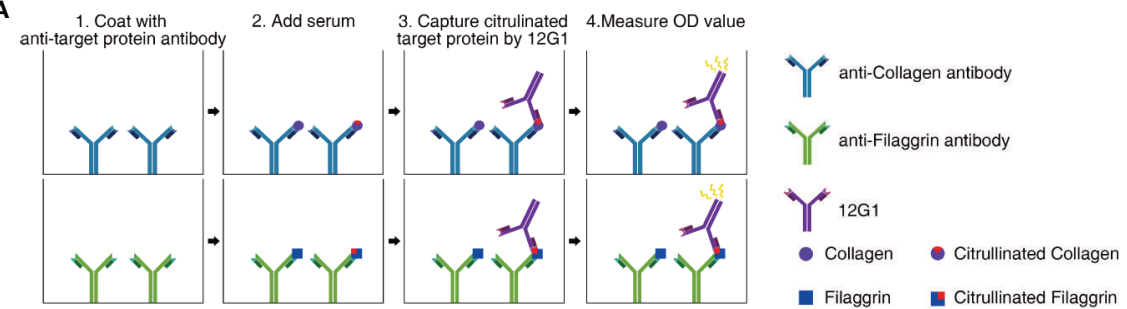

B
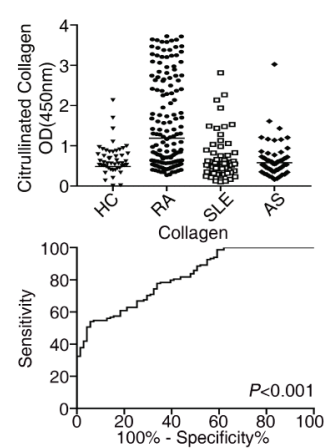

C
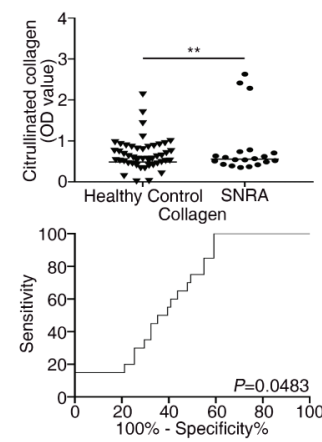

D

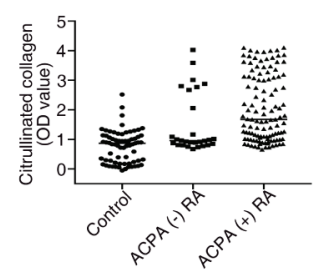

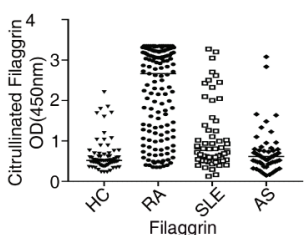

E
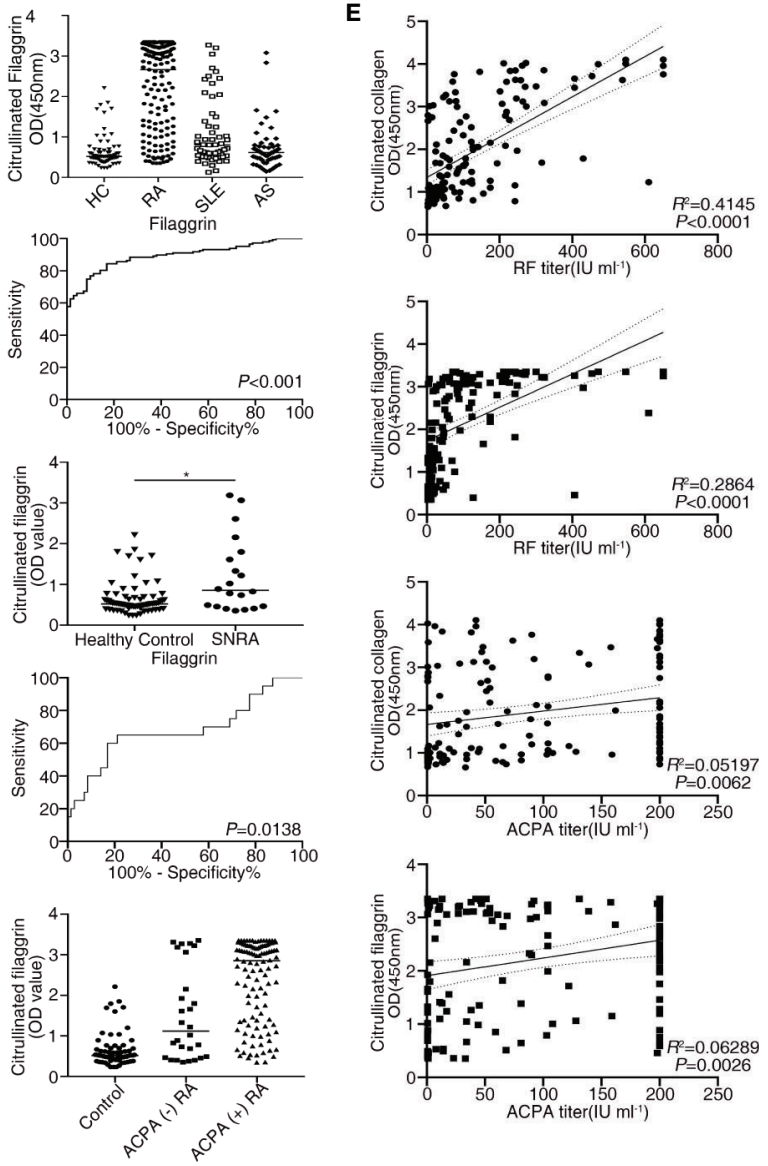
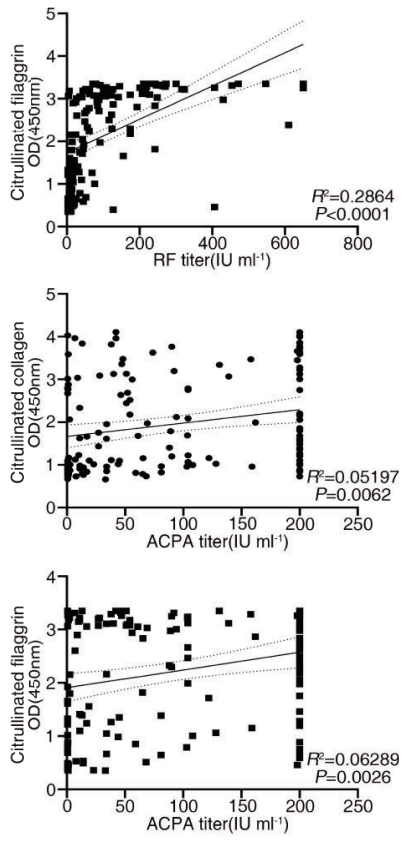

FIGURE 3 | Receiver operating characteristic (ROC) curve analysis comparing the sensitivity and specificity of the ELISA for measuring the levels of citrullinated collagen, and citrullinated filaggrin in patient serum. Anti-collagen, and anti-filaggrin were coated onto plates to capture the candidate antigens. Citrullination was detected by the 12G1. (A) Schematic diagram showing the method for the sandwich ELISA using an anti-target protein antibody and 12G1. (B) Circulating citrullinated antigens in serum samples from RA $(n=148)$, SLE $(n=60)$, AS $(n=57)$ patients and control subjects $(n=71)$ (upper row) and the ROC curve for each target antigen (lower row). (C) Circulating citrullinated antigens in the sera of seronegative RA $(n=20)$ and control subjects $(n=71)$ (upper row) and the ROC curve for each target antigen (lower row). Specificity (true negative rate [the percentage of RA patients correctly predicted]) is plotted on the $x$-axis, and sensitivity (the percentage of RA patients correctly predicted) is plotted on the $y$-axis. Calculations were based on the predicted probability of each subject being above the cutoff OD values. $P$ values were calculated using the Mann-Whitney $U$ test. ${ }^{*} P<0.05$. (D) OD values of three circulating citrullinated autoantigens for the control, ACPAnegative RA, and ACPA-positive RA subjects. (E) Correlations between circulating citrullinated collagen and filaggrin OD values and RF titers $(n=146, r=0.644$ for collagen, $r=0.535$ for filaggrin, $P<0.0001$ ), and ACPA titers $(n=143, r=0.228$ for collagen, $r=0.251$ for filaggrin, $P<0.01$ ) in RA patients (Pearson's correlation coefficient). ${ }^{* *} \mathrm{P}<0.01$.

and the AUCs were used to calculate the diagnostic accuracy of target antigens (Figures 3B, C and Supplementary Table 2). The sensitivity, specificity, likelihood ratio, positive predictive value (PPV), negative predictive value (NPV), and accuracy of RA diagnosis according to the presence of citrullinated filaggrin were
$78.9 \%, 85.9 \%, 5.6,92 \%, 66.3 \%$, and $80.8 \%$, respectively, when using an OD cut-off value of 1.013. Changing the OD cut-off value changed the sensitivity, specificity, PPV, NPV, and accuracy (Table 2). Interference by RF that might have caused additional false-positive activity was not present in our 12G1- 
TABLE 1 | Clinical and laboratory findings in healthy controls and RA patients.

\begin{tabular}{|c|c|c|c|}
\hline & $\begin{array}{l}\text { Healthy controls } \\
\qquad n=71\end{array}$ & $\begin{array}{c}R^{a} \\
n=148\end{array}$ & $P$ value \\
\hline Age (years) & $55.5 \pm 7.4$ & $57.2 \pm 12.2$ & NS \\
\hline Women & $62(83.7 \%)$ & 106 (71.6\%) & NS \\
\hline Disease duration (years) & & $3.5 \pm 4.5$ & \\
\hline RA onset age (years) & & $54.2 \pm 13.1$ & \\
\hline $\mathrm{ESR}^{\mathrm{b}}(\mathrm{mm} / \mathrm{h})$ & & $37.7 \pm 27.9$ & \\
\hline $\mathrm{CRP}^{\mathrm{C}}(\mathrm{mg} / \mathrm{dl})$ & & $0.93 \pm 1.82$ & \\
\hline $\mathrm{RF}^{\mathrm{d}}$-positivity & $0(0)$ & $105(71 \%)$ & \\
\hline $\mathrm{ACPA}^{\mathrm{e}}$ positivity & $0(0)$ & $118(79 \%)$ & \\
\hline Seropositive RA & & $128(86 \%)$ & \\
\hline $\operatorname{ERA}^{f}$ (<6 months) & & $52(35.1 \%)$ & \\
\hline EORA $^{9}$ (onset age $\geq 60$ years) & & $43(29.1 \%)$ & \\
\hline$T x^{h}$ naïve & & 42 (28.4\%) & \\
\hline \multicolumn{4}{|l|}{ Current medication } \\
\hline Methotrexate & & 87 (82\%) & \\
\hline Leflunomide & & 31 (29\%) & \\
\hline Tacrolimus & & $11(10 \%)$ & \\
\hline Sulfasalazine & & $13(12 \%)$ & \\
\hline Hydroxychloroquine & & $29(27 \%)$ & \\
\hline Biologics use & & $5(4.7 \%)$ & \\
\hline Prednisolone use (\%) & & $66(65 \%)$ & \\
\hline Mean prednisolone dose (mg/day) for the past month & & $2.7 \pm 2.7$ & \\
\hline
\end{tabular}

Data are expressed as the mean $\pm S D$ or number (percentage).

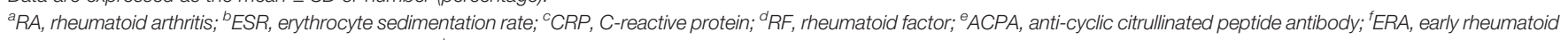
arthritis; ${ }^{g}$ EORA, elderly onset rheumatoid arthritis; ${ }^{h} T X$, treatment. NS means No significant.

based ELISA system (data not shown). Taken together, these results suggest that citrullinated collagen and filaggrin levels in serum could be a useful biomarker for the diagnosis of RA.

\section{Circulating Citrullinated Antigens Are Also Detected in Seronegative RA Patients}

Because the 1987 ACR criteria for RA diagnosis have low sensitivity and specificity, especially for patients with ERA (32), a new classification system for RA has been developed (22). Although the new criteria coupled with ACPA testing have improved the early diagnosis of RA, a negative result for autoantibodies (negativity for both RF and ACPA) does not rule out a diagnosis of RA. About $20 \%$ of RA patients are seronegative, meaning that no serological markers can be easily detected in the serum of these patients. Nonetheless, early diagnosis of seronegative RA is clinically important to prevent the progression of joint damage. Thus, novel diagnostic methods are needed to detect seronegative RA. In this study, the circulating level of citrullinated collagen and filaggrin was significantly higher in the sera from seronegative RA patients $(n=20)$ than in the controls, even though the number of samples from seronegative RA patients was small (Figure 3C and Supplementary Table 1).

Citrullinated collagen and filaggrin levels in sera of ACPApositive RA patients were significantly higher than those of ACPA-negative RA patients or healthy controls. Interestingly, the mean $O D$ values of both citrullinated collagen and fibronectin in the sera from ACPA-negative RA patients showed a statistically significant higher level than from healthy controls (Figure 3D).

These results suggest that some RA patients could have circulating citrullinated antigens but not ACPAs. Therefore, using $12 \mathrm{G} 1$ in an ELISA system could detect circulating citrullinated antigens and thereby aid the diagnosis of RA. Confirmation of these results in a large cohort of patients with seronegative RA is needed to determine whether this is a new method for diagnosing RF-negative, ACPA-negative RA.

TABLE 2 | Receiver-operating characteristic curve analysis of the sensitivity, specificity, positive predictive value, negative predictive value, and accuracy for differentiating between healthy controls and rheumatoid arthritis patients according to circulating citrullinated filggrin level.

\begin{tabular}{|c|c|c|c|c|c|c|c|c|c|c|c|c|}
\hline \multicolumn{7}{|c|}{ Control vs. $\mathrm{RA}^{\mathrm{a}}$} & \multicolumn{6}{|c|}{ Control vs. Seronegative RA } \\
\hline$>0.527$ & 91.1 & 54.9 & 2.023 & 80.7 & 75 & 79.4 & 65 & 54.9 & 1.442 & 28.9 & 84.8 & 57.1 \\
\hline$>1.013$ & 78.9 & 85.9 & 5.603 & 92.0 & 66.3 & 80.8 & 40 & 85.9 & 2.84 & 47.4 & 84.7 & 76.9 \\
\hline$>1.709$ & 65.9 & 95.7 & 15.62 & 97.0 & 57.6 & 75.7 & 25 & 97.5 & 5.917 & 53.3 & 84.2 & 79.1 \\
\hline
\end{tabular}

${ }^{a} R A$, rheumatoid arthritis; ${ }^{b} P P V$, positive predictive value; ${ }^{c} N P V$, negative predictive value. 


\section{Serum Citrullinated Collagen Levels Correlate With Autoantibody Titers}

We next examined the relationships between clinical characteristics and the levels of citrullinated autoantigens in RA patients to determine whether the presence of citrullinated antigens has clinical significance. The levels of none of the citrullinated antigens examined correlated with RA disease activity measured using a disease activity score of 28 , erythrocyte sedimentation rate (ESR), and C-reactive protein (CRP) (data not shown). Citrullinated collagen and citrullinated filaggrin levels in sera did not differ between established RA ( $>6$ months duration) and ERA or young-age onset RA (onset age $<$ 60 years) and EORA. Interestingly, the OD values for citrullinated collagen and filaggrin correlated significantly with autoantibody titers for both RF and ACPA (Figure 3E).

\section{Another Application for the 12G1 mAb: As a Mouse Model for RA}

We organized a new animal model using the aACPA (Materials and Methods and Figure 4A). We expected the 12G1 mAb to be as effective as the CIA model because previous research reported that citrullination could increase the potency of an endogenous innate immune ligand (33). CCP chelating bead was used to create a negative control in our $12 \mathrm{G} 1 \mathrm{mAb}$-induced arthritis model. After binding CCP chelating beads to protein A and G of $\mathrm{mAb} 12 \mathrm{G} 1$ 's IgG binding site, only the supernatant was inoculated into mice. We measured the arthritis score once every 3 days for 55 days after the first immunization. The score on the 55th day was the highest in the CIA group, the most commonly used standard animal model of RA, followed by the $12 \mathrm{G} 1 \mathrm{mAb}$ with LPS group and the $12 \mathrm{G} 1 \mathrm{mAb}$ only group.
A

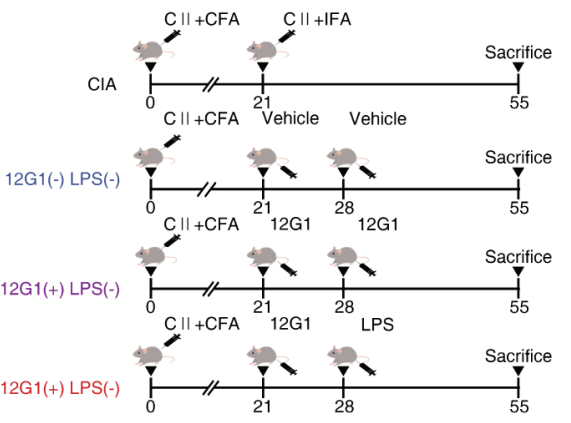

C
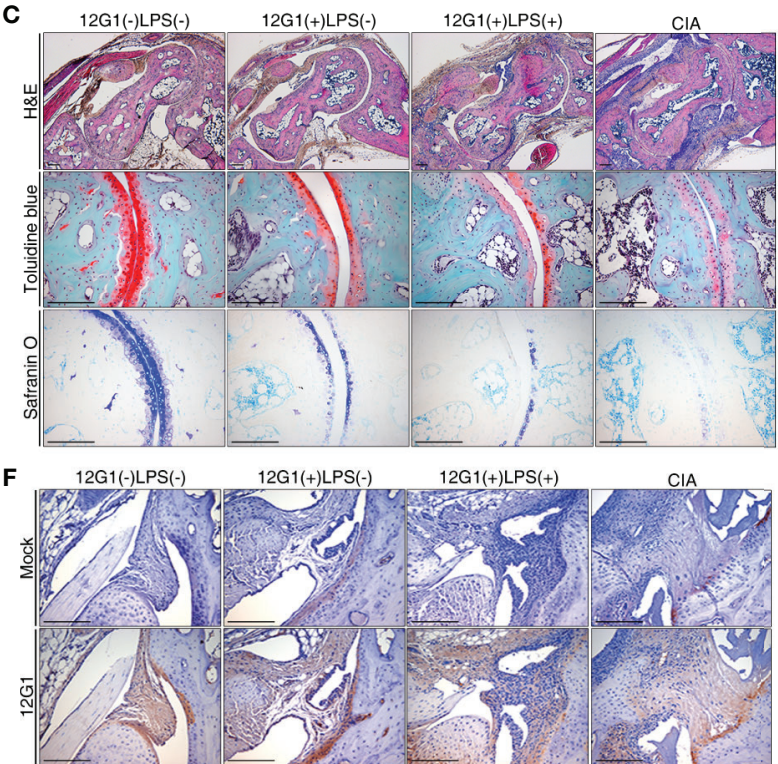

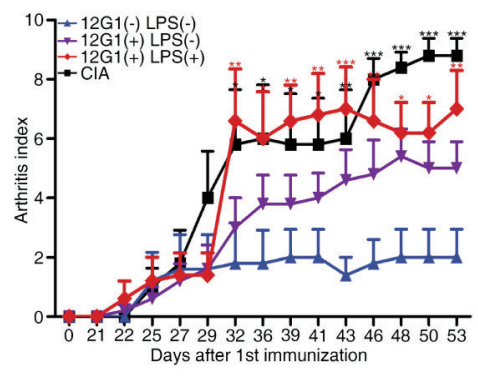

D
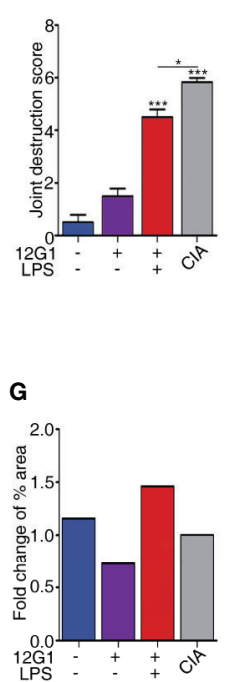

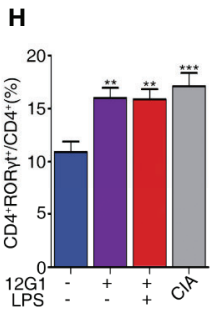

FIGURE 4 | A new animal model using $12 \mathrm{G} 1 \mathrm{mAb}$ was constructed, and its function was confirmed by comparison with the collagen induced arthritis (CIA) model. (A) Schematic diagram of the CIA animal model (a standard model of rheumatoid arthritis) and the animal model using the aACPA. (B) Average arthritis scores for the animal models. This score is expressed on a scale of $0-4$ as the sum of the arthritis severity scores for the four paws of each animal. (C) Histological analysis of the tarsals in the hind paws of each group stained with hematoxylin and eosin (H\&E), safranin O, and toluidine blue. H\&E-stained sections were magnified 50x and 100x; safranin $\mathrm{O}$ and toluidine blue samples are shown at 200x magnification. Histological scores were calculated as joint destruction scores (D) and inflammation scores (E) by three observers in a blind manner. (F) Immunohistochemical $(\mathrm{IHC})$ staining of citrullinated proteins in the tarsals, magnified 100x. (G) Measurement of the $12 \mathrm{G} 1 \mathrm{mAb}$ positive cell area per whole tarsal joint area by the Slide scanner program (3D Histech Ltd, Budapest, Hungary). (H) Flow cytometry analysis of the CD4 and RORyt expression in the spleens of each group. The percentages of CD4+ RORyt+ divided by total CD4+ indicate the frequency of Th17 cells. All scale bars are $200 \mu \mathrm{m}$, and all graphs are expressed using the mean \pm SEM. ${ }^{\star} P<0.05 ;{ }^{\star \star} P<0.01 ;{ }^{\star \star *} P<0.001$. 
The vehicle-treated group showed only a minor inflammatory response in the joints (Figure $\mathbf{4 B}$ ).

To analyze the infiltration of inflammatory cells, we measured the shape of cartilage and joint destruction in the tarsals using a histological analysis. In the CIA and $12 \mathrm{G} 1 \mathrm{mAb}$ with LPS groups, we observed more infiltration of immune cells and joint destruction than in the $12 \mathrm{G} 1 \mathrm{mAb}$ only group, though the $12 \mathrm{G} 1 \mathrm{mAb}$ with LPS group had slightly higher cartilage erosion than the other groups with the same arthritis score (Figure 4C). Both the inflammation score and joint destruction score were higher in the CIA and 12G1 with LPS groups than in the other groups, with small differences between them (Figures 4D, E).

In immunohistochemical staining and immunofluorescence assays, we used the $12 \mathrm{G} 1 \mathrm{mAb}$ to check the amount of citrullinated protein in the joints. The $12 \mathrm{G} 1 \mathrm{mAb}$ with LPS group had more citrullinated protein than the CIA group (Figure 4F). This result was consistent when we cross-checked it with the Slide scanner viewer program (Figure 4G).

To compare the Th17 response, the Th17 population determined by CD4+ROR $\gamma \mathrm{t}+$ expression was analyzed by flow cytometry. The results showed that Th17 cell populations were higher in the CIA and 12G1-treated groups than in the vehicle group (Figure $\mathbf{4 H}$ ).

\section{DISCUSSION}

The artificial mAb 12G1 described herein showed high reactivity for citrullinated peptides and proteins. 12G1 detected citrullinated proteins in RA synovial tissues and was used in an ELISA to detect circulating citrullinated autoantigens in RA serum. Among the potential citrullinated autoantigen targets examined, citrullinated filaggrin showed the highest sensitivity, specificity, PPV, NPV, and diagnostic accuracy for RA, suggesting its potential as a diagnostic serological marker for RA.

Although it is not easy to detect citrullinated proteins (either whole or fragmented), previous studies have identified the presence of citrullinated autoantigens in serum, synovium, and SF from RA patients $(5,30,34-37)$. Interestingly, there were two other similar attempts to detect citrulline residue of autoantigens. The first study was not designed to identify citrullinated proteins directly and chemical modification induced by incubating samples with diacetyl monoxime and antipyrine in a strong acid mixture was used to recognize citrulline (18). About 20 years ago, Nicholas and Whitaker generated a mAb, which they designated F95, that recognized citrullinated epitopes on a deca-citrulline peptide (19). By contrast, we here generated the $\mathrm{mAb} 12 \mathrm{G} 1$ to detect naïve citrullinated proteins directly. The ability of the $12 \mathrm{G} 1 \mathrm{mAb}$ to detect three potential citrullinated autoantigens (collagen, filaggrin, and fibronectin) was verified in our sandwich ELISA system.

Our mAb was generated against a synthetic peptide comprising a cyclic peptide harboring a single citrulline residue, that should allow the generation of a high-reactivity
$\mathrm{mAb}$. Our present study showed that the $12 \mathrm{G} 1 \mathrm{mAb}$ has the potential to directly detect citrullinated antigens in target tissues using immunohistochemistry. Generating a mAb by changing only a single citrulline residue (CCP versus the argininesubstituted NCP) could provide a better method for detecting naturally occurring citrullinated proteins than using the decacitrullinated peptide. The major advantage of our mAb $12 \mathrm{G} 1$ is that it can detect citrullination in the sera and synovia of RA patients without prior modification of the test samples.

To investigate the concordance between the presence of circulating citrullinated autoantigens and ACPAs, we used a commercially available second-generation ACPA test to examine the sera from 115 ACPA-positive RA patients. Most of the patients whose samples exhibited mAb 12G1-reaching citrullinated proteins were also positive for ACPA (data not shown).

Interestingly, the mAb 12G1-based ELISA revealed that some ACPA-negative RA patients also had circulating citrullinated proteins. We used the $12 \mathrm{G} 1 \mathrm{mAb}$-based ELISA to measure the levels of candidate proteins, including collagen, filaggrin, and fibronectin. We believe that the sensitivity and specificity of the $12 \mathrm{G} 1 \mathrm{mAb}$ as an RA diagnostic tool could be increased by broadening the range of target proteins and choosing different optimal cutoff values for each serological assay.

Our finding, that circulating citrullinated antigens can be detected by the 12G1-based ELISA system in RA patients at concentrations higher than those detected in healthy subjects, is consistent with a recent report implicating in vivo citrullination and subsequent production of ACPAs in the pathogenesis of RA $(38,39)$. Immunohistochemical staining detected reactivity in RA-affected synovia, whereas no positive signal was found in OA-affected or healthy synovial tissues. Our preliminary study also shows that the concentration of circulating citrullinated collagen in RA patients correlated positively with autoantibody titers (RF and ACPAs). These results suggest that the mAb 12G1 could be a useful tool in the diagnosis of RA.

\section{DATA AVAILABILITY STATEMENT}

The original contributions presented in the study are included in the article/Supplementary Material. Further inquiries can be directed to the corresponding authors.

\section{ETHICS STATEMENT}

The studies involving human participants were reviewed and approved by the Institutional Review Board of Seoul St. Mary's Hospital. The patients/participants provided their written informed consent to participate in this study. The animal study was reviewed and approved by the Institutional Animal Care and Use Committee of the School of Medicine at the Catholic University of Korea. 


\section{AUTHOR CONTRIBUTIONS}

PW and S-JM designed the experiments. PW and YK performed the experiments and analyzed the results. S-JM performed and analyzed the results of the human samples. HJ, AR, and DS carried out the experiments and data analysis. PW, S-JM, and JJ wrote the manuscript. JJ and WR helped analyze the results. All authors read and approved the final draft of the manuscript. All authors contributed to the article and approved the submitted version.

\section{FUNDING}

This work was supported by the Basic Science Research Program through the National Research Foundation of Korea (NRF), funded by the Ministry of Science, ICT, \& Future Planning

\section{REFERENCES}

1. Klareskog L, Lundberg K, Malmstrom V. Autoimmunity in Rheumatoid Arthritis: Citrulline Immunity and Beyond. Adv Immunol (2013) 118:129-58. doi: 10.1016/B978-0-12-407708-9.00003-0

2. Vossenaar ER, Nijenhuis S, Helsen MM, van der Heijden A, Senshu T, van den Berg WB, et al. Citrullination of Synovial Proteins in Murine Models of Rheumatoid Arthritis. Arthritis Rheum (2003) 48:2489-500. doi: 10.1002/ art.11229

3. Baeten D, Peene I, Union A, Meheus L, Sebbag M, Serre G, et al. Specific Presence of Intracellular Citrullinated Proteins in Rheumatoid Arthritis Synovium: Relevance to Antifilaggrin Autoantibodies. Arthritis Rheum (2001) 44:2255-62. doi: 10.1002/1529-0131(200110)44:10<2255::aidart388>3.0.co;2-

4. Foulquier C, Sebbag M, Clavel C, Chapuy-Regaud S, Al Badine R, Mechin MC, et al. Peptidyl Arginine Deiminase Type 2 (PAD-2) and PAD-4 But Not PAD-1, PAD-3, and PAD-6 Are Expressed in Rheumatoid Arthritis Synovium in Close Association With Tissue Inflammation. Arthritis Rheum (2007) 56:3541-53. doi: 10.1002/art.22983

5. Matsuo K, Xiang Y, Nakamura H, Masuko K, Yudoh K, Noyori K, et al. Identification of Novel Citrullinated Autoantigens of Synovium in Rheumatoid Arthritis Using a Proteomic Approach. Arthritis Res Ther (2006) 8:R175. doi: 10.1186/ar2085

6. Chang X, Zhao Y, Wang Y, Chen Y, Yan X. Screening Citrullinated Proteins in Synovial Tissues of Rheumatoid Arthritis Using 2-Dimensional Western Blotting. J Rheumatol (2013) 40:219-27. doi: 10.3899/jrheum.120751

7. Girbal-Neuhauser E, Durieux JJ, Arnaud M, Dalbon P, Sebbag M, Vincent C, et al. The Epitopes Targeted by the Rheumatoid Arthritis-Associated Antifilaggrin Autoantibodies are Posttranslationally Generated on Various Sites of (Pro)Filaggrin by Deimination of Arginine Residues. I Immunol (1999) 162:585-94.

8. Schellekens GA, de Jong BA, van den Hoogen FH, van de Putte LB, van Venrooij WJ. Citrulline Is an Essential Constituent of Antigenic Determinants Recognized by Rheumatoid Arthritis-Specific Autoantibodies. J Clin Invest (1998) 101:273-81. doi: 10.1172/JCI1316

9. Firestein GS. Evolving Concepts of Rheumatoid Arthritis. Nature (2003) 423:356-61. doi: 10.1038/nature01661

10. Kampstra ASB, Dekkers JS, Volkov M, Dorjée AL, Hafkenscheid L, Kempers AC, et al. Different Classes of Anti-Modified Protein Antibodies Are Induced on Exposure to Antigens Expressing Only One Type of Modification. Ann Rheum Dis (2019) 78:908-16. doi: 10.1136/annrheumdis-2018-214950

11. Romero V, Fert-Bober J, Nigrovic PA, Darrah E, Haque UJ, Lee DM, et al. Immune-Mediated Pore-Forming Pathways Induce Cellular Hypercitrullination and Generate Citrullinated Autoantigens in Rheumatoid [grant numbers 2019R1A5A2027588, 2020R1A2C3004123], and the Institute of the Clinical Medicine Research of Bucheon St. Mary's Hospital, Research Fund [grant number BCMC16IH01].

\section{ACKNOWLEDGMENTS}

The authors are grateful to Prof. Yong-suk Jang for technical assistance.

\section{SUPPLEMENTARY MATERIAL}

The Supplementary Material for this article can be found online at: https://www.frontiersin.org/articles/10.3389/fimmu.2021.692242/ full\#supplementary-material
Arthritis. Sci Transl Med (2013) 5:209ra150. doi: 10.1126/scitranslmed. 3006869

12. Titcombe PJ, Wigerblad G, Sippl N, Zhang N, Shmagel AK, Sahlström P, et al. Pathogenic Citrulline-Multispecific B Cell Receptor Clades in Rheumatoid Arthritis. Arthritis Rheumatol (2018) 70:1933-45. doi: 10.1002/art.40590

13. Steen J, Forsström B, Sahlström P, Odowd V, Israelsson L, Krishnamurthy A, et al. Recognition of Amino Acid Motifs, Rather Than Specific Proteins, by Human Plasma Cell-Derived Monoclonal Antibodies to Posttranslationally Modified Proteins in Rheumatoid Arthritis. Arthritis Rheumatol (2019) 71:196-209. doi: 10.1002/art.40699

14. Kongpachith S, Lingampalli N, Ju CH, Blum LK, Lu DR, Elliott SE, et al. Affinity Maturation of the Anti-Citrullinated Protein Antibody Paratope Drives Epitope Spreading and Polyreactivity in Rheumatoid Arthritis. Arthritis Rheumatol (2019) 71:507-17. doi: 10.1002/art.40760

15. Elliott SE, Kongpachith S, Lingampalli N, Adamska JZ, Cannon BJ, Mao R, et al. Affinity Maturation Drives Epitope Spreading and Generation of Proinflammatory Anti-Citrullinated Protein Antibodies in Rheumatoid Arthritis. Arthritis Rheumatol (2018) 70:1946-58. doi: 10.1002/art.40587

16. Ge C, Xu B, Liang B, Lönnblom E, Lundström SL, Zubarev RA, et al. Structural Basis of Cross-Reactivity of Anti-Citrullinated Protein Antibodies. Arthritis Rheumatol (2019) 71:210-21. doi: 10.1002/art.40698

17. Tilvawala R, Nguyen SH, Maurais AJ, Nemmara VV, Nagar M, Salinger AJ, et al. The Rheumatoid Arthritis-Associated Citrullinome. Cell Chem Biol (2018) 25:691-704.e6. doi: 10.1016/j.chembiol.2018.03.002

18. Senshu T, Sato T, Inoue T, Akiyama K, Asaga H. Detection of Citrulline Residues in Deiminated Proteins on Polyvinylidene Difluoride Membrane. Anal Biochem (1992) 203:94-100. doi: 10.1016/0003-2697(92)90047-b

19. Nicholas AP, Whitaker JN. Preparation of a Monoclonal Antibody to Citrullinated Epitopes: Its Characterization and Some Applications to Immunohistochemistry in Human Brain. Glia (2002) 37:328-36. doi: 10.1002/glia.10039

20. Koh E-M, Kim J, Kim T-G, Moon J-H, Oh J-H, Lee J-Y, et al. Cloning and Characterization of Heavy and Light Chain Genes Encoding the FimASpecific Monoclonal Antibodies That Inhibit Porphyromonas Gingivalis Adhesion. Microbiol Immunol (2011) 55:199-210. doi: 10.1111/j.13480421.2011.00305.x

21. Arnett FC, Edworthy SM, Bloch DA, McShane DJ, Fries JF, Cooper NS, et al. The American Rheumatism Association 1987 Revised Criteria for the Classification of Rheumatoid Arthritis. Arthritis Rheum (1988) 31:315-24. doi: $10.1002 /$ art.1780310302

22. Aletaha D, Neogi T, Silman AJ, Funovits J, Felson DT , Bingham CO3rd, et al. 2010 Rheumatoid Arthritis Classification Criteria: An American College of Rheumatology/European League Against Rheumatism Collaborative Initiative. Arthritis Rheum (2010) 62:2569-81. doi: 10.1002/art.27584 
23. Rudwaleit M, van der Heijde D, Landewé R, Listing J, Akkoc N, Brandt J, et al. The Development of Assessment of SpondyloArthritis International Society Classification Criteria for Axial Spondyloarthritis (Part II): Validation and Final Selection. Ann Rheum Dis (2009) 68:777-83. doi: 10.1136/ ard.2009.108233

24. Petri M, Orbai AM, Alarcón GS, Gordon C, Merrill JT, Fortin PR, et al. Derivation and Validation of the Systemic Lupus International Collaborating Clinics Classification Criteria for Systemic Lupus Erythematosus. Arthritis Rheum (2012) 64:2677-86. doi: 10.1002/art.34473

25. Wruck CJ, Fragoulis A, Gurzynski A, Brandenburg LO, Kan YW, Chan K, et al. Role of Oxidative Stress in Rheumatoid Arthritis: Insights From the Nrf2-Knockout Mice. Ann Rheum Dis (2011) 70:844-50. doi: 10.1136/ ard.2010.132720

26. Huckel M, Schurigt U, Wagner AH, Stockigt R, Petrow PK, Thoss K, et al. Attenuation of Murine Antigen-Induced Arthritis by Treatment With a Decoy Oligodeoxynucleotide Inhibiting Signal Transducer and Activator of Transcription-1 (STAT-1). Arthritis Res Ther (2006) 8:R17. doi: 10.1186/ $\operatorname{ar} 1869$

27. Rim YA, Yi H, Kim Y, Park N, Jung H, Kim J, et al. Self In Vivo Production of a Synthetic Biological Drug CTLA4Ig Using a Minicircle Vector. Sci Rep (2014) 4:6935. doi: 10.1038/srep06935

28. Park N, Rim YA, Jung H, Kim J, Yi H, Kim Y, et al. Etanercept-Synthesising Mesenchymal Stem Cells Efficiently Ameliorate Collagen-Induced Arthritis. Sci Rep (2017) 7:39593. doi: 10.1038/srep39593

29. Schellekens GA, Visser H, de Jong BA, van den Hoogen FH, Hazes JM, Breedveld FC, et al. The Diagnostic Properties of Rheumatoid Arthritis Antibodies Recognizing a Cyclic Citrullinated Peptide. Arthritis Rheum (2000) 43:155-63. doi: 10.1002/1529-0131(200001)43:1<155::Aidanr20>3.0.Co; $2-3$

30. Masson-Bessiere C, Sebbag M, Girbal-Neuhauser E, Nogueira L, Vincent C, Senshu T, et al. The Major Synovial Targets of the Rheumatoid ArthritisSpecific Antifilaggrin Autoantibodies are Deiminated Forms of the Alphaand Beta-Chains of Fibrin. J Immunol (2001) 166:4177-84. doi: 10.4049/ jimmunol.166.6.4177

31. Shelef MA, Bennin DA, Mosher DF, Huttenlocher A. Citrullination of Fibronectin Modulates Synovial Fibroblast Behavior. Arthritis Res Ther (2012) 14:R240. doi: 10.1186/ar4083

32. Banal F, Dougados M, Combescure C, Gossec L. Sensitivity and Specificity of the American College of Rheumatology 1987 Criteria for the Diagnosis of Rheumatoid Arthritis According to Disease Duration: A Systematic Literature
Review and Meta-Analysis. Ann Rheum Dis (2009) 68:1184-91. doi: 10.1136/ ard.2008.093187

33. Sokolove J, Zhao X, Chandra PE, Robinson WH. Immune Complexes Containing Citrullinated Fibrinogen Costimulate Macrophages via Toll-Like Receptor 4 and Fcgamma Receptor. Arthritis Rheum (2011) 63:53-62. doi: 10.1002/art.30081

34. Chang X, Yamada R, Suzuki A, Kochi Y, Sawada T, Yamamoto K. Citrullination of Fibronectin in Rheumatoid Arthritis Synovial Tissue. Rheumatol (Oxford) (2005) 44:1374-82. doi: 10.1093/rheumatology/kei023

35. Skriner K, Adolph K, Jungblut PR, Burmester GR. Association of Citrullinated Proteins With Synovial Exosomes. Arthritis Rheum (2006) 54:3809-14. doi: 10.1002/art.22276

36. Raijmakers R, van Beers JJ, El-Azzouny M, Visser NF, Bozic B, Pruijn GJ, et al. Elevated Levels of Fibrinogen-Derived Endogenous Citrullinated Peptides in Synovial Fluid of Rheumatoid Arthritis Patients. Arthritis Res Ther (2012) 14: R114. doi: 10.1186/ar3840

37. Kimura E, Kanzaki T, Tahara K, Hayashi H, Hashimoto S, Suzuki A, et al. Identification of Citrullinated Cellular Fibronectin in Synovial Fluid From Patients With Rheumatoid Arthritis. Mod Rheumatol (2014) 24:766-9. doi: $10.3109 / 14397595.2013 .879413$

38. Uysal H, Bockermann R, Nandakumar KS, Sehnert B, Bajtner E, Engstrom A, et al. Structure and Pathogenicity of Antibodies Specific for Citrullinated Collagen Type II in Experimental Arthritis. J Exp Med (2009) 206:449-62. doi: 10.1084/jem.20081862

39. Uysal H, Nandakumar KS, Kessel C, Haag S, Carlsen S, Burkhardt H, et al. Antibodies to Citrullinated Proteins: Molecular Interactions and Arthritogenicity. Immunol Rev (2010) 233:9-33. doi: 10.1111/j.0105-2896. 2009.00853.x

Conflict of Interest: The authors declare that the research was conducted in the absence of any commercial or financial relationships that could be construed as a potential conflict of interest.

Copyright (C) 2021 Won, Kim, Jung, Rim, Sohn, Robinson, Moon and Ju. This is an open-access article distributed under the terms of the Creative Commons Attribution License (CC BY). The use, distribution or reproduction in other forums is permitted, provided the original author(s) and the copyright owner(s) are credited and that the original publication in this journal is cited, in accordance with accepted academic practice. No use, distribution or reproduction is permitted which does not comply with these terms. 